\title{
Ethnologies
}

\section{Henri Lefebvre, Space and Folklore}

\section{Tim B. Rogers}

Volume 24, numéro 1, 2002

Espace

Space

URI : https://id.erudit.org/iderudit/006529ar

DOI : https://doi.org/10.7202/006529ar

Aller au sommaire du numéro

\section{Éditeur(s)}

Association Canadienne d'Ethnologie et de Folklore

ISSN

1481-5974 (imprimé)

1708-0401 (numérique)

Découvrir la revue

Citer cet article

Rogers, T. B. (2002). Henri Lefebvre, Space and Folklore. Ethnologies, 24(1), 21-44. https://doi.org/10.7202/006529ar

\section{Résumé de l'article}

Nous explorons la pensée complexe d'Henri Lefebvre concernant l'espace, ainsi que ses implications pour les ethnologues, au moyen d'une conversation fictive entre Lefebvre et l'auteur de cet article, au cours d'une promenade dans une petite ferme du sud-est de la Colombie britannique. Certains aspects des points de vue de Lefebvre sont exposés et illustrés à partir d'exemples se présentant sur place, tels que des clôtures ou des emplacements de feux de camp. Le schéma tripartite de Lefebvre pour conceptualiser l'espace s'articule dans le cours de la conversation, en mettant en avant l'importance du concept souvent éludé d'“ espace vécu ». Nous voulons démontrer que considérer l'espace de cette manière dialogique, inclusive et ouverte, amènerait à une régénération et à une approche potentiellement transformative de notre compréhension de l'espace - une approche qui aurait de nombreuses implications dans l'étude des traditions culturelles.
Ce document est protégé par la loi sur le droit d'auteur. L'utilisation des services d'Érudit (y compris la reproduction) est assujettie à sa politique d'utilisation que vous pouvez consulter en ligne.

https://apropos.erudit.org/fr/usagers/politique-dutilisation/ 


\title{
Henri Lefebvre, Space ANd Folklore
}

\author{
Tim B. Rogers \\ University of Calgary
}

Every now and again our scholarly notions are put to a real test in the context of our day-to-day lives, forcing us to ground our comfortable academic abstractions in the complex hurly-burly of our own daily existence. This happened to me recently when I took possession of a small, 50 acre farm in rural British Columbia. Originally conceived as a place for quiet, contemplative writing and an opportunity to come closer to the wildness of the region, this piece of land soon began poking and prodding me with a series of challenges that have had tremendous impact upon my views of social tradition and, in a very broad sense, my understandings of folklore. As I scurried about trying to address these challenges, scouring library shelves and chatting with colleagues and neighbours, I came face-to-face with the importance of space. I began to recognize that this place in the south-east corner of $\mathrm{BC}$, with its strange buildings in unexpected places, its fences totally independent of surveyed property lines, its piles of what seemed to be garbage all over the place, its seemingly random trenches and pathways, its unfamiliar codes of staining and whitewashing buildings, and its many other mysteries, demanded a much more complicated and sophisticated view of space than I'd held earlier. Indeed, the farm emerged as a conundrum, forcing me to actively reconsider my conception of space.

For me, a breakthrough came when I encountered the thinking of Henri Lefebvre. Here I found a series of ideas that began to clarify space and that took me beyond my previously limited and foreclosing ideas. His vision of space opened up a number of avenues of thought that provided new insights and ideas about this strange-seeming place in the East Kootenays of British Columbia. I began to see space as a complex, multifaceted and intermixed series of different domains in which the relational and dialogic have precedence over the static and 




Henri Lefebvre (1901-1991). Photograph taken from Edward W. Soja, 1996, Thirdspace: Journeys to Los Angeles and Other Real-And-Imagined Places. Oxford UK: Blackwell, p. 25, (C) John Friedmann. Permission requested. 
realist notions I'd held earlier. Indeed, space came to life in Lefebvre's ideas.

\section{Henri Lefebvre (1901-1991)}

Lefebvre is considered by many to be the patron saint of the study of space. ${ }^{1}$ His rescue of space from the scholarly, Cartesian shadows which it occupied in much of Western intellectual thought is celebrated as a landmark achievement by many scholars in geography, urban studies, architecture, and other "spatial" disciplines. But, the more I read him the more I recognized that there is a sense in which his insights transcend the disciplinary affiliations that deal explicitly with the spatial, to the point that his thinking is highly relevant to a wide range of scholarly projects. Indeed, it seems clear that Lefebvre's work has deep and significant implications for scholars, like folklorists, whose work foregrounds the notion of "culture. ${ }^{\text {" }}$

The more I worked though Lefebvre's seminal book, La production d'espace $^{3}$, the more I began to appreciate the complexities of how the realist's version of space as "out there" and independent of our involvement in it (his first space), and the manner in which we talk about and represent this complex topic (his second space), served to create difficulties. The most critical of these was how the realism underlying first space and the primacy of second space in our culture occluded important concerns, making it almost impossible to voice a full idea of space within our academic traditions. It soon became clear that Lefebvre's third space, a dialogical field linking people and their

1. Autobiographical information can be found in Lefebvre (1959). Biographical information can be found in Harvey (1991); Soja (1996: Chapter 1); Hess (1988).

2. Lefebvre talks about "social space" continuously throughout The Production of Space, the seminal presentation of his spatial critique. Indeed, social space appears to be the major focus of this work. This interpretation is complicated, though, by his evocation of many different forms and numbers of "spaces" in the midst of which it is sometimes difficult to determine his exact position; see Dear (1996).

3. This book, while one of a series of seven in which Lefebvre developed his spatial critique, is thought to be the most definitive statement of his position (1974/1991). Unless otherwise noted, references to Lefebvre hereafter will be to this volume. 
worlds, fell between the cracks of most academic treatises rendering his vibrant understanding of space almost ungraspable.

These concerns were amplified the more I tried to write about these occlusions. I found the writing traditions we use unreflexively in the academy were not up to the task of fully articulating Lefebvre's complex and complicated third space. These traditions, by virtue of being located in the second space of representation create a strait jacket for the writer, making it exceedingly difficult to articulate the subtleties of the dialogical and relational field that forms the core of Levebvre's ideas. Standard didactic writing styles, while partially useful, never seemed to be quite up to the job of bringing Lefebvre's vibrant ideas into clear focus.

In an effort to break out of this strait jacket I began to experiment with alternate writing forms. To the extent that Lefebvre's third space was, at heart, dialogic and relational, it seemed appropriate to adopt a dialogic and relational writing style. This might, at least to a degree, provide a more congenial approach to articulating Lefebvre. The present paper is an effort to do this by situating an exploration of Lefebvre's ideas in a fictitious conversation with him, held as we are walking around the farm in BC. By grounding presentation of his ideas in this dialogical form, it may be possible to more clearly engage the rich and relational aspects of Lefebvre's thinking. Perhaps in this way we can begin to lay the groundwork for appropriation of some of his ideas to the study of folklore. ${ }^{4}$ So let's go for a walk.

\section{Lefebvre's Notion of Folklore}

"Monsieur Lefebvre" I said tentatively as we begin to stroll out toward the fence that marks the northern boundary of our farm, "you mentioned folklore in several places in your book, The Production of Space."

"Hmm," he replied a bit uncertain of himself, "refresh my memory."

"Well," I ventured, trying my best to remember how he had voiced this view. "You argued that any social entity that can be considered

4. The scholarly burden of the writing approach here is carried in the footnotes, many of which present excerpted quotes from Lefebvre's work that are representative of the point being made in the conversation. Other footnotes provide background information relevant to the idea being discussed. 
'real' must produce its own space and that any entities which don't do this would eventually become folklore and disappear".

"Ah yes, I recall now," he said, his face lightening up. "My point there was to make it clear that every society must produce its own space. You must remember that space is not some vacuum waiting to be filled by people, but rather it is actively constructed and produced. Societies that fail to produce their own special spaces simply don't survive — rather they recede into folklore."

"I see," I ventured a bit uncertainly. "You are using the term folklore in the sense of it being mythology or ideology, ${ }^{6}$ suggesting that this is all that would be left if there was no special social space."

"Yes," Lefebvre replied. "I believe I made that point quite clearly when I was discussing Heidigger's ${ }^{7}$ and Bachelard's ${ }^{8}$ concepts of home. There I argued that the notion of 'home', with all of its warm and fuzzy connotations is a carryover from premodern times. I also suggested it lies at the heart of the paradox of modernity. The notion of home has a kind of poetic reality that is sustained by folklore and, if I recall correctly, I suggested this was problematic for understanding space. ${ }^{9}$

5. 'Any 'social existence' aspiring or claiming to be 'real,' but failing to produce its own space, would be a strange entity, a very peculiar kind of abstraction unable to escape from the ideological or even the 'cultural' realm. It would fall to the level of folklore and sooner or later disappear altogether, thereby immediately losing its identity, its denomination and its feeble degree of reality" (Lefebvre 1974/1991: 53). “... new social relationships call of a new space, and vice versa" (59).

6. Lefebvre was a self-described Marxist (Soja 1996: 33), perhaps explaining this use of folklore-as-ideology. He was an active member of the party until 1954 when he was ushered out by virtue of his challenging Stalinist dogma and, at least in part, by his desire to broaden Marx's position. While somewhat oversimplified, Lefebvre wanted to recenter Marx, away from the workplace and its struggles, toward life as lived in the capitalist dominated world (e.g., Lefebvre : 82-83; 325-344). He, like Foucault and many French intellectuals, was deeply affected by the student uprisings of May 1968 which challenged many of the tenets of traditional Marxist thought, leading to renewed intellectual discourse. Interestingly, Lefebvre, as a nearby academic activist, was a "player" in these student uprisings.

7. Lefebvre cited: Heidigger (1954/1971) especially the chapter entitled "Das Ding"/"The thing."

8. Lefebvre cited: Bachelard (1957/1969).

9. In discussing the emergence of modernity: "So far as space is concerned, decisive changes occurred at this juncture which are effectively obscured by invariant, 
"So do you construct folklore as a problem which interferes with aspects of understanding space?" I asked.

"I suppose so." Henri mused as we entered an uncultivated field, full of small white and purple wild flowers. "I definitely see it as involving an appeal to obsolete ways of thinking - as relating to quaint aspects of lived experience which can get in the way of the effective understanding of space." 10

"That's interesting," I replied. "Over here in North America many scholars have a different view of folklore. It is not seen as the negative, ideological villain you seem to be talking about, but rather is seen as a positive aspect of how people interact within given groups, like at work or in various social situations."

Lefebvre paused for time to think and then ventured, "That's interesting. I can see how viewing folklore that way could be quite useful. It might be possible to see how people resist power and change their worlds by taking that view." He paused again. "There does, indeed, seem to be some good potential there." 11

Then he changed tack. "Tell me, where did this particular idea of folklore come from?"

"Well, there's a fairly long tradition of looking at it this way," I said somewhat hesitantly. "I first encountered it when I spent some time with folklore scholars in Newfoundland." Henri seemed a bit puzzled. "You mean there are actually folklore departments in universities over here?"

surviving or stagnant elements, especially on the plane of representational space. Consider the house, the dwelling. In the cities - and even more so in the 'urban fabric' which proliferates around the cities precisely because of their disintegration - the House has a merely historico-poetic reality rooted in folklore, or (to put the best face on it) in ethnology. This memory, however, has an obsessive quality: it persists in art, poetry, drama and philosophy. What is more, it runs through the terrible urban reality which the twentieth century has instituted, embellishing it with a nostalgic aura ..." (120-121).

10. "New ideas (socialism, for instance), though not without force, have difficulty generating their own space, and often run the risk of aborting; in order to sustain themselves, they may appeal to an obsolete historicity, or assume folkloric or quaint aspects" (417).

11. This point foreshadows an aspect of Lefebvre's third space which will be taken up later in our conversation. 
"Yep," I responded. "There're a few at least."

"Mon dieu," he said, looking skyward. "Does this mean that folklore, like history, sociology and the other disciplines has organized itself into a 'chapelle'?"

"A chapelle?" I queried.

"Yes, yes, one of those aggravating cliques or schools that always seems to dominate intellectual life. ${ }^{12}$ " He seemed genuinely perturbed as we strolled toward the edge of the field. "I've always held that abstraction, the currency of les chapelles, is inherently violent. ${ }^{13}$ It seduces us away from engaging the realities of lived experience and the spaces which are both created by it and frame it." He went on with renewed passion, "Even words, viewed as signs of things, are terribly violent and destructive because they abstract and destroy ${ }^{14}$ - I even once called them 'harbingers of death' (134) - because they can break and disassemble beings. The words themselves are mere shadows of what they represent."15

\section{Studying Space is Difficult}

Trying to make sense of this outburst I haltingly suggested, "So you seem to be saying that there are a lot of factors that get in the way of understanding space. So far you've mentioned les chapelles as doing violence here, mostly through how they involve abstraction, and your view of folklore because it offers mythologies that interfere with engaging space. I presume there are other things that make space so hard to study as well."

Henri responded with a wry smile, "No doubt, there are many more." For emphasis, he grabbed the first finger on his left hand and began to

12. Lefebvre (1975). See Soja (1996: 32-36) for a discussion.

13. "... 'the logic of space' (as we study it in the academy), with its apparent significance and coherence, actually conceals the violence inherent in abstraction" (306; entry in braces added); see also: 289-290.

14. "... the sign has the power of destruction because it has the power of abstraction" (135).

15 " ... all signs are bad signs, threats and weapons. ... They are doubles of things. When they assume the properties of things, when they pass for things, they have the power to move us emotionally, to cause frustrations, to engender neuroses. As replicas capable of disassembling the 'beings' they replicate, they make possible the breaking and destruction of those beings" (134). 
count off on his fingers: "Descartes and his pesky division between things cognitive and material; the fetishization of mathematics; philosophy especially epistemology and realism; semiotics and discourse; history with its implicit emphasis of time over space ${ }^{16}$ come to mind - but there are more, many more." He stopped, I think simply because he'd run out of fingers/thumbs upon which to count. He continued, "If I were a conspiracy theorist, I'd suggest that almost all of our scholarly activity is aimed at hiding the foundational importance of space. All of the things I've mentioned," holding up his hand with all five digits clearly showing to make his point, "and more, tend to obscure, or perhaps more properly occlude, full engagement with space. That's why it is so difficult to study - that's why it has remained a mute, backstage player in the grand intellectual debates of our times. ${ }^{17}$ "

As we walked in silence along the northern boundary of the farm I tried to contemplate what a study of space, liberated from the violence of our scholarly abstractions, might look like. Lefebvre seemed to understand my wondering and stopped. Then, in a quiet voice, he said, "Take this fence for example."

"Yes" I replied.

"If we use words to describe it - what do you call it, a 'barbed wire fence'? - we've already done violence to it. There is so much we've left out when we describe it like that, so much."

Still a bit uncertain of what he meant, I asked, "But how can we come to understand this fence then? Where do we start?"

16. All of these are discussed in detail in Lefebvre: 1-32.

17. At this point, I reminisced to myself about the similarity of this argument to that offered by many scholars attempting to resurrect the physical, corporeal body from the scholarly shadows to which it has been consigned (e.g., Radley 1991; Shilling 1993; Butler 1993). Interestingly, Lefebvre anticipated this embodiment argument in his approach to space. "Western philosophy has betrayed the body" (57). "The whole of (social) space proceeds from the body, even though it so metamorphizes the body that it may forget it altogether - even though it may separate itself so radically from the body as to kill it" (405). "Fluctuations in the use of measures, and thus in representations of space, parallel general history and indicate the direction it has taken... towards the elimination of the body" (111). "In seeking to understand... space, it may help to consider the body. (...) social practice presupposes the use of the body: the use of the hands, members, and sensory organs, and the gestures of work as of activity unrelated to work" (40). 


\section{First Space: Espace perçu}

Stroking his chin, Lefebvre stood facing the fence and began to answer. "I've found that it is useful to begin by thinking of such things in three different ways. ${ }^{18}$ I've named each of these as particular kinds of space, but I've found it convenient to think of them as registers or clefs, each of which is essential to a full understanding of the spatial. First", again grabbing a finger on his left hand, "is what I like to call espace perçu. ${ }^{19}$ This is the materialized, socially-produced space that exists empirically. It is directly sensible or perceivable - open to measurement and description. It is both the medium and the outcome of human activity, behaviour and experience. ${ }^{20}$ This fence, for example, can be understood using espace perçu by noting how it has constructed a pathway or route parallel to it - the one we're walking on. Here, in this pathway, we see the spatial impact of generations of farmers as they ply their daily chores of checking the fences, looking for livestock, and any number of routine chores." ${ }^{21}$

18. Lefebvre preferred triads in almost all of his analyses. This was in part to resist binaries: "A desire to avoid dialectical thought is what lies at the root of this search" (293), and also to explore moving beyond them. In his reading of Lefebvre, Edward Soja (1996) has called this movement toward "threes" trialectics. There is an appeal to this label, in the manner in which it harkens back to dialectics, given the Hegelian and Marxist heritage from which Lefebvre began his scholarly journey. However, Lefebvre was quite anti-Hegelian in a number of places in The Production of Space (e.g. 238, 280) which cautions against a wholesale adoption of the connotations of the term "trialectics."

19. Literally "perceived space." I've found it useful to retain the French names for the "spaces" in what follows because these concepts do not seem to survive translation into our academic ethos very well. For instance, the term "perceived" has been so strongly appropriated by North American psychology (as the interpretive end of sensation), that we almost unconsciously fall into a passive, information processing understanding of "perceived space." This is definitely not what Lefebvre intended.

20. Espace perçu "embraces production and reproduction, and the particular locations and spatial sets characteristic of each social formation. Spatial practice (which is an integral part of espace perçu) ensures continuity and some degree of cohesion. In terms of social space, and of each member of a given society's relationship to that space, this cohesion implies a guaranteed level of competence and a specific degree of performance." (33).

21. Pathways were important to Lefebvre's position: "Traversed now by pathways and patterned by networks, natural space changes: one might say the practical activity writes upon nature, albeit in a scrawling hand, and that this writing 
"Yeah," I said, "you can almost see the Swiss farmer who built this fence in 1937 shuffling along to bring in his cows for milking."

Lefebvre, oblivious to my reverie, continued, "But there's more. Another aspect of espace perçu is the manner in which it reveals spaces that humans have produced. It embraces production and reproduction in many ways." He walked over to the fence and knelt down, softly stroking one of the bushes that had sprouted beneath it, its woody branches and green leaves weaving their way between the rows of wire. "What's this?" he asked smelling one of the white, bract-like flowers on the plant.

"A saskatoon bush," I replied. "In July, those flowers will become juicy, purple berries, not unlike blueberries. They're pretty good eating."

Still holding the blossom in his hand, he continued quietly: "Have you ever thought that this bush, no matter how 'natural' it seems, is here because of human production? It's all part of a cycle of production of space — social space." 22

"Well...," I stammered not quite sure how to respond.

Lefebvre continued, "The only reason this bush is here is because your Swiss pioneer built this fence — right?" Obviously a rhetorical question, he continued, "The presence of this fence has created a very special space in which your beloved saskatoons, and the many other plants we see here, can flourish. Certainly if the fence was not here, this bush would have fallen prey to the yearly mowing and bailing that takes place here — right?"

I nodded in silent agreement.

"In effect, the special space under this fence reveals a very complex set of social practices. These emerge in not only the kinds of things that have been done to this land near the fence, but also in the things prohibited by the constructed space. This space, indeed, has been

implies a particular representation of space" (117-118). "Paths are more important than the traffic they bear (because) such traces embody the 'values' assigned to particular routes: danger, safety, waiting, promise" (118; entry in braces added). Since Lefebvre's call to studying space, pathways have emerged as particularly salient examples of the spatiality of social practices. See, for example, Ingold (1993); Macnaughten and Urry (1998: Chapter 5).

22. "(Social) space is a (social) product" which will be "revealed in its particularity" $(26-27)$. 
produced." ${ }^{23} \mathrm{He}$ paused, as if to get ready to make an important point. "In my view we have underestimated the importance of this kind of production of space. We seem to prefer seeing these kinds of produced space as some kind of neutral backdrop to our other activities rather than fully appreciating how much production is actually involved. But, in actuality, the space itself, which we produced, has deep and significant impact on everything we do."

"How..." I began to stammer.

"For example," he said, showing a bit of impatience at my slowness, "the fence frames the pathway we can take while on this most pleasant walk — we can't walk through it - we can only walk along it. Look at your dog there. She moves under the fence as if it isn't there - her activity isn't constrained by the fence. But ours is. The fence frames our activity in many subtle ways - it, and the lovely little ecosystem it has created, is not a neutral stage but an integral part of what we are able to do, what we actually do, and what we've done in the past."

"I see," I ventured hesitantly. "The fence seems to provide limits on what we can do. It facilitates some actions and prohibits others... gee, that's interesting." 24

My co-walker looked over at me with a bemused, yet tolerant look signaling my restatement of the obvious. "Looking at this fence in terms of espace perçu reveals the dialogic, back-and-forth between humans and space that is so important. This is what gets lost if we treat space as a neutral, pregiven container of our actions, and shows how important space is."

Slowly, I was beginning to understand the rich and vibrant conceptualizaton of space with which Lefebvre was working. Quietly, to myself, I mused, "All that from just looking at an old fence."

23. Lefebvre emphasizes prohibition in the creation of social space, making this fence example, in which space was created by not permitting mowing etc., appropriate: "... the ultimate foundation of social space is prohibition" (Lefebvre 1974/1991-2: 35).

24. In some work in ecological psychology, these kinds of facilitations and constraints on action are called affordances. They are environmental factors that serve to shape dialogue with the world in a number of important ways which are often not noticed by the participants in the space. This is argued in detail in Rogers (2001). 


\section{Second Space: Espace conçu}

I was furiously trying to relate these insights to how we could study culture. But before I could get very far he continued, "Don't forget that this espace perçu is just one of three ways of examining space. It is nowhere near a complete picture. Whatever you do, don't totalize this space to the exclusion of the others, else we get back to the violence we talked about earlier."

"If that's the case then, what's the next space we should explore?" I asked, eager to move on.

Lefebvre then put up two fingers, in the sign for victory, and said, "Now to the second espace." He paused, and then continued, "Let's imagine that we've gone back to the cabin and are sitting in front of the fire talking about our fence here. What would we talk about?"

Not being sure of how to answer, I wondered out loud, "Perhaps we'd begin to chat about how we conceptualized the fence - the words, the ideas, the understandings we'd used to try and make sense of it."

“Exactement!" Henri responded more enthusiastically than I'd expected, "and that is our next espace. I like to call it espace conçu. ${ }^{25}$ Here we're talking of the world of signs, codes and discourses we have about space. ${ }^{26}$ Sometimes I like to think of this as the domain of propositional knowledge - the space where scientists, planners, technocrats, even some artists hang out. It includes the discursive resources that embody the relationships of power, control and production - a semiotic space if you will. It also draws heavily on texts and logos, being a kind of 'mental space' which contains

25. Literally "conceived space." In translation, this has emerged as "representations of space" drawing on the manner in which the domain entails the manner in which spaces are constructed (represented) in our verbal and conceptual discourses about space. I've shied away from using this name because of the manner in which it seems to accept, unreflexively, the notion of representation - a notion that appears to be incompatible with Lefebvre's "antiabstraction" argument.

26. Espace conçu is "tied to the relations of production and to the 'order' which those relationships impose, and hence to knowledge, to signs, to codes and to 'frontal' relations" (33). In this excerpt, the term "signs" is meant to apply to the more or less standard semiotic meaning, "codes" can be read as "discourses" although they are not exclusively verbal in Lefebvre's view, and "frontal" relations, I believe, relate to the surface (or phenotypal) views of the relations involved. 
representations of ideology and surveillance. And, perhaps of greatest import, espace conçu is the dominant space in our world."27

"So how does this play out when we talk about the fence?" I queried.

"Well," he replied, "let's think for a moment about the functions of this fence. Why is it here?"

I paused, realizing I hadn't thought of this before. "I guess its main function is to keep the neighbour's cows out of my alfalfa."

"Ah yes," Lefebvre returned, "the fence, then, serves to REPRESENT some important issues regarding production and ownership." $\mathrm{He}$ underlined the word "represent" with a strong inflection as he voiced the word. "You lose revenue if your neighbour's cows break in and trample or eat your alfalfa, right?"

"Yes," I answered.

Lefebvre continued, "So the fence comes to represent critical things about production — indeed, it comes to represent your very ownership and control of this piece of land. Does not the fence effectively mark your ownership of the farm?" Without giving me a chance to respond, he continued, "In this espace, then, the fence evokes all kinds of texts - your deed of ownership, a whole canon of laws regarding property rights, reams of documentation regarding agricultural practices and much, much more. All of these things are part and parcel of espace conçu. They are representations of aspects of your space here."

"But," I said, "the fences don't run along the property lines here. They appear to have been put there for convenience, not to mark a survey line."

"That doesn't really matter," he said briskly. "The point is that the fence has come to represent your ownership of the alfalfa field — right?" I nodded, still a bit uncertain about his meaning. "The physical aspects of whether the fence runs on the property line is the domain of espace perçu; in our second space we're concerned with how it is represented in our talk about it — that's the important thing."

I wanted him to elaborate this point so asked, "What about unwritten codes of conduct? You know those things we know when we're in a

27. Lefebvre has asserted that espace conçu is the dominant space of all societies, not just ours. I don't find his arguments about this potential universality to be particularly persuasive so have chosen the less ambitious framing of relating this dominance to our society. 
group but often aren't represented in texts. I'm thinking of things such as keeping fences like this one mended and other aspects of cooperation among farmers - things that we just 'know' by being part of the group." 28

"Hmm," Lefebvre responded, clearly looking inward for an answer. "I'd guess they'd be included here in espace conçu as well, especially if they were represented in texts like proverbs, song lyrics, jokes, stories and such. If they aren't represented in this kind of text, which is unlikely, then I'd guess these unwritten codes would belong more to the realm of the third space I'll be talking about later on. But I'd guess most of these informal rules would wiggle their ways into espace conçu texts, one way or another."

The words to an old Cole Porter song appropriated to folk tradition flitted momentarily through my mind, "Oh give me land lots of land and the starry skies above, don't fence me in." I suddenly realized that Lefebvre may well be right here, the informal codes do, indeed, appear to get articulated in nontraditional texts of the kind often studied in folklore — and they do have significant spatial content. Briefly I considered an intriguing prospect for studying folklore by examining how various spatial issues become voiced in the traditional folklore genres. Say proverbs - "a man's home is his castle"-, or humour the legions of joke cycles that serve to exclude "others" from a particular space, or stories and myths about finding home, and more. All of these take on a new meaning when viewed spatially. I began to sense considerable potential for folklloristics in foregrounding the spatial.

Lefebvre recognized my reverential tangent and paused for a moment. He then summarized, "It is important to remember that this second space contains the manner in which the elements observed in espace perçu are conceived or represented. It is not an empirical world of social practices, but a conceptual world of representations of these and other things."

I was astounded that standing looking at this simple fence could lead to all of this talk of the grandest of social and intellectual accomplishments and concerns.

Lefebvre continued, "I should mention here that many scholars are biased toward studying these representations and frequently end up mistaking them for the 'real' thing. Indeed, les chapelles are particularly

28. There are many examples of this kind of unwritten rule in the folklore literature. One example of many possible is Rogers (1987). 
guilty of this. It is in this misidentification of text with reality that space recedes into the background and tends to become invisible." ${ }^{29}$

By now my mind was full of dizzying ideas as I tried to grasp the implications of Lefebvre's spatial treatise. But again he would not give me the time to work these out, rather he pushed even further.

\section{Third Space: Espace vécu}

"Now we come to the hard part," Henri mused as we both continued to look at the barbed wire fence in front of us. He held up three fingers and indicated, "You're going to have to let go of some of your traditional ways of thinking if you want to understand my third space ${ }^{30}$ - what I call espace vécu. ${ }^{31}$ This is space as directly lived - the space of inhabitants and users. It is not simply espace perçu which contains empirical space and the social forces of production, or espace conçu which contains representations of these, but it is the space of actual life, the space of virtual interchange between humans and their constructed, spatial worlds." 32

29. Several examples: he suggests that Derrida and Barthes are "forever promoting the basic sophistry whereby the philosophico-epistemological notion of space (his espace conçu) is fetishized and the mental realm comes to envelop the social and physical ones. (Most of these authors) spring without the slightest hesitation from mental to social" (5-6; entries in braces added). "Most if not all authors ensconce themselves comfortably enough within the terms of mental (and therefore neo-Kantian or neo-Cartesian) space, thereby demonstrating that 'theoretical practice' is already nothing more than the egocentric thinking of specialized Western intellectuals - and indeed may soon be nothing more than an entirely separated, schizoid consciousness" (Lefebvre: 24).

30. More than any other treatment of Lefebvre I've encountered, Soja's (1996) Chapter 2, entitled "The Trialectics of Space," brings home the manner in which this third space demands a renewed imagination and reconceptualization of how we think.

31. Literally lived space which is "space as directly lived through its associated images and symbols, and hence the space of 'inhabitants' and 'users,' but also of some artists and perhaps of those, such as a few writers and philosophers, who describe and aspire to do no more than describe. This is the dominated - and hence passively experienced - space which the imagination seeks to change and appropriate. It overlays physical space, making symbolic use of its objects" (39).

32. "Codes will be seen as part of a practical relationship, as part of an interaction between 'subjects' and their space and surroundings. I shall attempt to trace the 
"So would this third space involve lived interchanges with the world - like what we're having right now as we walk and talk by this fence?" I asked tentatively.

"Indeed," Lefebvre responded. "It is the here-and-now of lived existence that frames espace vécu. As you can see it is something different from our first two spaces by virtue of the manner in which it foregrounds

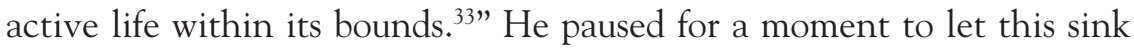
in and then proceeded cautiously, "Yet, while it is different from espaces perçu and conçu, it also encompasses them. Perceived and conceived spaces are important components of a person's lived experience, hence espace vécu is BOTH distinct from AND encompasses the other two spaces." He was able to underscore the "both" and the "and" in this sentence with his voice and using a strange pointing gesture.

I was a bit unsure of what he meant at this point and asked tentatively, "So let's bring this back to the fence." I paused trying to gather my thoughts, "The elements of espace perçu, like the paths and social practices the fence engenders, and the aspects of espace conçu like conceptions of ownership and production the fence represents are different from this third, lived espace vécu."

"Yes," Henri said quietly, "espace vécu is a very special place of lived social space."

"But," I continued, "you're also saying that this third space encompasses the other two spaces as well. You're saying that it's both different and the same - all at once. ${ }^{34}$ I must say I find that a bit confusing - maybe even contradictory." ${ }^{15}$

coming-into-being and disappearance of codings/decodings. My aim will be to highlight contents - the social (spatial) practices inherent to the forms under consideration" (18).

33. 'This space qualifies as a 'thing/not thing,' for it is neither a substantial reality nor a mental reality, it cannot be resolved into abstractions... it has an actuality other than that of the abstract sign and real things which it includes" (402).

34. It would be unfair to present Lefebvre without indicating that he is a very tough read - in part because some of his ideas do not translate into English particularly well and, perhaps more importantly, because he seems to delight in contradiction and forcing readers beyond their current thinking. Soja (1996: 64) described him rather accurately as "trenchantly unsystematic". See Merrifield (1995: 294-303) for further discussion of this.

35. "No science of space... can brook contradictions in the nature of space. If social space were constituted by dualities (or dual properties), these could not embody contradictions in the nature of space" (292). 
He replied, "That's what I meant when I said you'd have to let go of some of your traditional ways of thinking to properly engage this third space. This domain of lived experience is, I believe, full of contradictions and seeming opposites. Indeed, this is one of its most endearing properties, making lived space mysterious, secretive — indeed extraordinary. ${ }^{36}$ If we try to conceive of it or translate it into discourse by mapping it into espace conçu we change it. If we try to perceptualize lived experience by bringing it into espace perçu we change it as well. It can only be understood on its own plane of lived experience in the here and now. It then becomes both/and as opposed to either/or."

Lefebvre sensed I was struggling with this and decided to change tack and provide an example. "Let's go back to the fence to see this kind of 'both/and' logic at work. On the one hand, as we walk beside the fence we are at the margins of your farm - after all the fence marks its boundary from your neighbours - it is at the edge, right? Yet as we walk and talk out here we are also in the centre of your farm by participating in social practices that define the very essence of this space. In this sense, we are simultaneously at the periphery and at the centre. There is a sense in which living action in this space allows us to see the centre and margins at the same time - this is the extraordinary aspect of espace vécu." 37

"Geeze," I ventured, "this seems to dissolve the strong binary distinction between center and periphery that characterizes so much of our contemporary thought."

Lefebvre nodded subtly and added, "Not only does the center/ periphery binary dissolve in my third space but most of the other dichotomies, those bugaboos created in second space, do as well. For example, notice how when we walk along this fence, it is silly to think of time and space as being different — they are both the same thing as we are bodily engaged in this particular activity. Nature and culture melt into a special kind of unity when we participate in embodied dialogue with our spatial surround. And there are more too," he concluded with a flourishy gesture upward.

36. The extraordinary and extra-discursive properties of espace vécu have been elaborated in Rogers (2000).

37. Soja (1996: Chapters 3 and 4) has presented a detailed analysis of how Lefebvre's destabilization of the centre-periphery binary (see Lefebvre: 398-400) is very congenial to a number of feminist and postcolonial theorists like bell hooks, Gloria Anzaldua, Gayatri Spivak, Edward Said, and Homi Bhabha. 
In an effort to get him to say more, I tentatively commented, "This sounds pretty mysterious, almost secretive, to me."

"Yes indeed," Henri replied, "it is. This is a veiled place - the lived space that is dominated - passive, muted, subjected. And, at the same time, though, it is an active place - the lived space of struggle, liberation, and emancipation."

"More of that both/and stuff, eh," I commented.

Lefebvre ignored me and carried on, "When we shed our preperceptions of espace perçu and our preconceptions of espace conçu, we begin to find this rich and vibrant world of espace vécu. However, the only way we can keep it at the forefront is to resist attempts of the other two spaces to dominate - hence espace vécu becomes a site of struggle - a site for the enactment of power.

\section{Walking Back Home}

Lefebvre seemed to be finished talking - although it was clear he had more, much more, to say. He turned abruptly and headed back toward the cabin. I scurried after him, asking about how these three spaces came together.

"The first thing," he said glancing over his shoulder at me, "is to recognize that this three space notion loses all of its power if we treat it like an abstract model. Because if we do this, all of its rich, concrete meaning falls out and it becomes a vehicle for nothing more than articulating ideology. ${ }^{38}$ While the triad is a way of reducing the problem of space to study it, you must take pains to 'unreduce' it and try to grasp the totality of space."

"That sounds like quite a challenge," I offered.

"Yes," he said quietly. "Sadly, les chapelles, with all of their specialized knowledge, have considerable trouble doing this, ${ }^{39}$ perhaps because it

38. "The perceived-conceived-lived triad (espaces perçu, conçu and vécu respectively) loses all force if it is treated as an 'abstract model.' If it cannot grasp the concrete (as distinct from 'immediate'), then its import is severely limited, amounting to no more than that of one ideological mediation among others" (40; entry in braces added).

39. "One of the misfortunes of the specialist is that he makes this methodological moment into a permanent niche for himself where he can curl up happily in the warm" (106). 
challenges their well drawn disciplinary fences. ${ }^{40 "}$ He paused briefly and continued, "Academics tend to overestimate their writing and theories, and in so doing wring the life out of lived experience. ${ }^{41}$ Only if we can keep the triad together, through the encompassing nature of espace vécu can we hope to engage space in a fulsome and generative way."

"Generative?" I asked.

"Yes, yes, by providing new openings, new ways of looking at things that allow us to escape the closed and preconceived ideas that ensnare our imaginations and make it so hard for us to fully understand space."

Lefebvre's pace had quickened now, and I was struggling to keep up with him as we rounded the corner and the cabin came into view. But the biggest struggle I was having was trying to figure out how I might adapt these ideas to exploring folklore. I knew, for example, that third space, espace vécu, was critical in any effort to understand folklore as performance - after all, any performance takes place on a particular spatial stage, and presumably such stages have their own spatial structures that enable or restrict particular kinds of relational activity. I was trying to put form onto this thought when Lefebvre stopped abruptly and turned around with a sly grin on his face.

"Look at this," he said pointing down to the ring of rocks that frames our fire pit and the lawn chairs carefully placed around it. "This is a pretty simple spatial arrangement isn't it?"

"Yeah," I ventured, finally able to catch up to him.

40. "We should not, therefore, be particularly surprised if the concept of the production of space, and the theory associated with it, were challenged by specialists who view social space through the optic of their methodology and their reductionistic schemata. This is all the more likely in view of the fact that both concept and theory threaten interdisciplinary boundaries themselves: they threaten, in other words, to alter, if not to erase, the specialists' carefully drawn property lines" (108).

41. "To underestimate, ignore and diminish space amounts to the overestimation of texts, written matter, and writing systems, along with the readable and visible, to the point of assigning to these a monopoly on intelligibility" (62). "Knowledge falls into a trap when it makes representations of space the basis for the study of 'life', for in doing so it reduces lived experience. ... 'Our' space thus remains qualified (and qualifying) beneath sediments left behind by history, by accumulation, by quantification" (230). 
"See how this simple arrangement of chairs around a fire is such an effective invitation to conversation. The warmth and colour of the fire, the lack of a dominant seating position, and the long social traditions of 'the campfire' combine to make this a rather special space which affords rather special kinds of dialogues of the kind we find in espace vécu."

I was shocked; it was as though he had read my mind about the spatial facilitations/restrictions of performance stages - here was a perfect example. The campfire, as a spatial arrangement first and foremost, has provided the setting in which generations of people participated in many of the traditions we've come to know as folklore. Clearly this simple spatial setting is an integral part of these various traditions. And more importantly, its "spatial" stamp must be imprinted on the texts that have emerged from this setting. I couldn't help but wonder why I hadn't thought of this before, but, recalling Henri's earlier comments about how space is hidden, was able to negate my emerging feelings of stupidity.

Lefebvre continued, "Think of this space in comparison to classrooms of the kind we find in our schools and universities. Neatly arranged in rows oriented toward the front of the room, these spaces are, in a very rudimentary way, invitations AGAINST conversation and dialogue. They privilege the voice of the person at the front of the room. And this is so readily visible when we foreground space." ${ }^{42}$

Again my mind was buzzing, as I tried to grapple with the implications of trying to take performance traditions born of the campfire and placing them into classroom-like spaces. It seems clear that the dialogic potentialities inherent in the "campfire traditions" are drastically changed when they are adapted to the nondialogic theatre. I recognized the possibility of a rich project examining changes to various performance traditions when they are moved into different spatial domains and the impacts these might have on the dialogic, third space, potentialities of the traditions. It was becoming clear to me that space could serve as a highly useful analytic perspective for folklore studies. "Maybe that explains why I feel so uncomfortable as a singer in the classroom," I mused to myself.

42. This is argued in detail in Rogers (2001). 
"And don't forget," Lefebvre continued, "that people are not passive prisoners of the spaces in which they find themselves. In many cases they creatively appropriate them. Things like carving names on desks in classrooms, graffiti, shuffling or renovating existing space, creating new spaces and more, all reveal resistances to power. And notice how these are readily observable, both in their textual and their social fabric, in a spatial analysis. It is here that we find the clandestine, mysterious and resistant elements of human conduct inscribed upon, and readable from, the produced spaces of a culture."

We both sat down in the inviting lawn chairs, soaking in the warm afternoon sun, and staring into the fireless campfire. I looked over at Lefebvre and realized that he was tired and wanted to retreat into his own personal espace vécu. All the while my mind buzzed with the potentialities for folklore studies that come of foregrounding space. As I scanned the farm, I began to recognize that our short conversation about space had increased my understanding considerably. The importance and significance of fences was clear, as was the generative possibilities this afforded. The way was now open to begin to ask about the social traditions and dialogical realities that led to the choice of barbed wire over other possibilities. The failure of the fences to follow property lines seemed to fall into the background when dialogic issues were foregrounded. The piles of garbage and discarded wood now became important sites of particular social practices once I began to conceive of them in terms of Lefebvre's third space. The possibility of exploring the strange whitewashing of the butt ends of the cabin logs now emerged as a challenge of reconstructing historical social practices and seeing how these were adapted to the BC wilderness. No doubt the Austrian/ Swiss connection of the cabin builder was involved, but the story remains to be discovered of the whys and wherefores of adapting this practice to BC. These, and the myriad of other ideas that came to me as I slowly scanned the spatial world of the farm, indicated very clearly that Lefebvre's ideas provide new horizons of understanding. I looked over at my conversational partner and saw him squinting into the afternoon sun, trying to find the source of muted sound at the border of the field and the trees. He was as engrossed in his exploration as I was in mine, trying to work out the potential of space for folkloristics. 


\section{Postconversational Considerations}

It is my view that Lefebvre's notion of third space as a relational and dialogical field that is simultaneously spatial/temporal, natural/ cultural, central/marginal and closed/open-ended offers a transformative view for folklore studies. Engaging this view leads to a revitalized view of material culture, offering an explicit way of constructing it as a site of power relations. Viewing folklore genres as revealing second space articulations of informal, sometimes hidden, dialogic and spatial third space practices opened the door to a transformative view of tradition. The notion of context as elemental in understanding folklore is, through his ideas, much more clearly articulable, particularly in light of how space both creates and is created by interchange. Performance is clarified in a spatial framework in which it is possible to envision the manner in which space constrains and facilitates certain kinds of activities. Crossvenue adaptations of folklore traditions become visible with the notions of spatial constraints and facilitations offering a useful investigative framework. Traditions of resistance became tractable within in this view. As I worked through the topics of the discipline of folklore, I came to realize that spatial analysis does indeed, to use Lefebvre's word, have considerable generative potential. It provides a perspective that allows us to see the discipline through very different lenses. In Lefebvre's third space, espace vécu, there is a transformative view that facilitates grasping the almost ungraspable elements of the dialogic and relational aspects of our spatial world.

In one sense Lefebvre's ideas are not that new. In my readings of folklore I've found a number of his ideas as well as some efforts to develop relational positions. What is different here, however, is the manner in which Lefebvre has been able to bring these scattered observations under the umbrella of a coherent theory of space. It is in this coherence that it may be possible to more fully articulate and appreciate the many aspects of space that our contemporary intellectual traditions occlude from our view. Of course, much work remains to be done. But for now there is a clear beginning with considerable potential.

While this fictitious conversation with Lefebvre still exists in the representational world of second space, it does, by virtue of its dialogic character, help to bring some aspects of space into clearer view. The notion of the rich, relational third space begins to come to life, at least 
a bit, in this chat with Henri. At the same time though it is still a pale approximation of the vibrant space that I've sensed in Lefebvre's writing. No matter how hard we try, second space, espace conçu, tends to dominate when we have to communicate in representational media such as writing. About the only solution here is to let go of some of our traditional ideas and to embrace the dialogic in its fullest aspect. While this will be a long term project, barely begun at this point, embracing third space will, I believe, lead us to a view of folklore studies which has considerable promise. 


\section{References}

Bachelard, Gaston. 1957/1969. La poétique de l'espace/The Poetic of Space.

Paris: Presses Universitaires de France/Boston MA: Beacon Press.

Butler, Judith. 1993. Bodies that Matter: On the Discursive Limits of "Sex".

New York: Routledge.

Dear, Michael. 1996. Postmodern Bloodlines. In Space and Social Theory:

Geographic Interpretations of Postmodernity, eds. Benko George and

Ulf Strohmayer. Oxford UK: Blackwell, 49-71.

Harvey, David. 1991. Afterward. In Lefebure, Henri. The Production of

Space. Cambridge MA: Cambridge, 425-343.

Heidigger, Martin. 1954/1971. Vortrage und Aufsatze/Poetry, Language, Thought. Pfullingen: Neske/New York: Harper and Row.

Hess, Rémi. 1988. Lefebure et l'aventure du siècle. Paris: Éditions A.M. Métailié.

Ingold, Tim. 1993. The Temporality of Landscape. World Archaeology, 25: $152-174$.

Lefebvre, Henri. 1959. La somme et le reste (2 volumes). Paris: La Nef de Paris.

-__-_. 1974/1991. La production de l'espace/The Production of Space. Paris: Anthropos/Oxford UK: Blackwell.

—. 1975. Le temps des méprises. Paris: Stock.

Macnaughten, Phil and John Urry. 1998. Contested Natures. London UK: Sage.

Merrifield, Andy. 1995. Lefebvre, anti-logos and Neitzsche: An Alternative Reading of The Production of Space. Antipode, 27: 294303.

Radley, Alan. 1991. The Body in Social Psychology. New York: Springler. Rogers. Tim B. 1987. The Strawberry Roan in Alberta: A Study of Regional Identity. Prairie Forum, 12: 75-93.

into a unified whole and deep ecology comes alive. Trumpeter, 16.1. http://trumpeter.athabascau.ca/content/v16.1/rogers.html

- 2001. Applying the Spatial Critique to Theory in Psychology: Toward a Useful Third Space. Paper read at the International Society for Theoretical Psychology. Calgary AB. June 2001 (presently under review).

Shilling, Curt. 1993. The Body and Social Theory. London: Sage.

Soja. Edward. 1996. Thirdspace: Journeys to Los Angeles and other real and imagined places. Oxford UK: Blackwell. 